\title{
Antimicrobial Activity and Action Approach of the Olive Oil Polyphenol Extract Against Listeria monocytogenes
}

\author{
Ling Guo', Qi Sun', Shaoying Gong ${ }^{1}$, Xue Bi ${ }^{1}$, Wen Jiang ${ }^{2}$, Wei Xue ${ }^{3}$ and Peng Fei ${ }^{4 *}$ \\ 'Key Laboratory of Dairy Science, Ministry of Education, College of Food Science, Northeast Agricultural University, Harbin, \\ China, ${ }^{2}$ National Agricultural Standardization Monitoring and Research Center (Heilongjiang), Harbin, China, ${ }^{3}$ Metrology \\ Institute of Measurement and Verification (Heilongjiang), Harbin, China, ${ }^{4}$ College of Food and Bioengineering, Henan \\ University of Science and Technology, Luoyang, China
}

OPEN ACCESS

Edited by:

Hua-Bin Li,

Sun Yat-sen University, China

Reviewed by:

Zihao Teng,

University of Amsterdam,

Netherlands

Ergin Murat Altuner,

Kastamonu University, Turkey

${ }^{*}$ Correspondence:

Peng Fei

feipeng0220@126.com;

736422337@qq.com

Specialty section:

This article was submitted to

Food Microbiology,

a section of the journal

Frontiers in Microbiology

Received: 04 April 2019 Accepted: 25 June 2019

Published: 23 July 2019

Citation:

Guo L, Sun Q, Gong S, Bi X, Jiang W, Xue W and Fei $P$ (2019)

Antimicrobial Activity and

Action Approach of the Olive Oil

Polyphenol Extract Against

Listeria monocytogenes.

Front. Microbiol. 10:1586.

doi: 10.3389/fmicb.2019.01586
Olive oil polyphenol extract (OOPE) has been reported to have antibacterial activity; however, its effect on Listeria monocytogenes is less studied so far. This study, thus, aimed to reveal its antimicrobial activity and action approach against $L$. monocytogenes via evaluating the minimum inhibitory concentration (MIC) as well as the changes of intracellular adenosine $5^{\prime}$-triphosphate (ATP) concentration, cell membrane potential, bacterial protein, DNA, and cell morphology. The results showed that OOPE could inhibit the growth of $L$. monocytogenes with a measured $\mathrm{MIC}$ of $1.25 \mathrm{mg} / \mathrm{ml}$. L. monocytogenes cells treated by OOPE showed significant reduction in intracellular ATP concentrations, bacterial protein, or DNA $(p<0.05)$, in comparison with those without any treatment. In addition, OOPE was observed to depolarize strain cells and alter cell morphology, resulting in damaged cell membrane and, thereby, leakage of cell fluid. These findings demonstrated that OOPE had inhibition on L. monocytogenes via its action on cells, suggesting its potential as a natural preservative.

Keywords: Listeria monocytogenes, olive oil polyphenol extract, antimicrobial activity, action approach, cellular morphology

\section{INTRODUCTION}

Listeria monocytogenes is a Gram-positive bacterium, and as one of the major food-borne pathogens, it is involved in some outbreaks of severe food-borne infections (Odedina et al., 2015). The survival and growth of L. monocytogenes are easy in the conditions of high salt concentration, low $\mathrm{pH}$, and low temperature, which increase its potential as a contaminant of food products (Allen et al., 2016). Fresh vegetables and fruits, dairy products, ready-to-eat foods, and food-contact surfaces are susceptible to contamination from L. monocytogenes (Hamidi-Oskouei et al., 2015). Currently, a variety of technologies and safety systems are implemented to control pathogens. However, the contamination of L. monocytogenes is still considered as a major food safety problem (Long et al., 2011).

Compared with synthetic preservatives, natural extracts have attracted great interest due to their ability to inhibit the growth of food-borne pathogens and not trigger negative safety worries (Rendueles et al., 2011). Some plant extracts had been well documented to be used as potential natural antimicrobial agents or preservatives against L. monocytogenes, such as fruit and vegetable extracts from mint and pomegranate, spice extracts from cinnamon and 
clove, and phenolic extracts from legumes processing by-products (Aureli et al., 1992; Araya-Cloutier et al., 2018; Xylia et al., 2018). Consumers are more willing to accept natural extracts as preservatives than synthetic preservatives due to the nature and relative safety of natural products (Fei et al., 2018). Therefore, people would like to learn more information about using plant extracts as potential preservatives for controlling L. monocytogenes.

Polyphenols have demonstrated a series of biological effects including antibacterial, antioxidants, anti-inflammatory, antiviral, and antiallergic action (Daglia, 2012; Borges et al., 2013). Olive oil polyphenol extract (OOPE) is a natural substance obtained from olive oil and contains abundant polyphenolic compounds (Bubonja-Sonje et al., 2011). Tafesh et al. (2011) reported that polyphenolic compounds separated from olive mill wastewater have good antibacterial activity against Gram-positive and negative bacteria. The study reported by Thielmann et al. (2017) proved that the extracts of olive leaves and fruits of Olea europaea Linné from Mediterranean countries also have higher effective antimicrobial activity in food matrices. In previous studies, the antibacterial effect of OOPE and its action approach against Cronobacter sakazakii and Bacillus cereus have already been reported by our team (Fei et al., 2018, 2019). Based on this evidence, it is reasonable to assume that OOPE can be used to inhibit L. monocytogenes as a potential natural bacteriostatic substance.

The purposes of this study were to evaluate the antibacterial activity of OOPE against L. monocytogenes and to elucidate the possible action approach through investigating the changes in intracellular adenosine $5^{\prime}$-triphosphate (ATP) concentration, cell membrane potential, bacterial protein, cell DNA, and cell morphology after treatment with OOPE.

\section{MATERIALS AND METHODS}

\section{Olive Oil Polyphenol Extract Materials}

OOPE was provided by Shanghai Kai Da Biotechnology Co. Ltd. (Shanghai, China). The chemical compositions of OOPE include moisture $(<7 \%)$, total polyphenols $(\geq 30 \%)$, hydroxytyrosol $(\geq 6 \%)$, tyrosol $(\geq 0.8 \%)$, phenolic acids $(\geq 1.5 \%)$, and ethanol $(<0.1 \%)$.

\section{Bacterial Strain and Culture Condition}

A total of eight L. monocytogenes strains were used in this study; among them, L. monocytogenes CMCC 54004 was obtained from the National Center for Medical Culture Collections (CMCC) of China, and the other seven strains were isolated from food samples. All isolates were used to assess the minimum inhibitory concentration (MIC), whereas L. monocytogenes CMCC 54004 was used to analyze the action approach of OOPE against L. monocytogenes. The strains were stored in Luria-Bertani (LB) broth with $20 \%$ glycerol (v/v) at $-80^{\circ} \mathrm{C}$. After being cultured in LB broth medium at $37^{\circ} \mathrm{C}$ with shaking at $150 \mathrm{rpm}$ for $24 \mathrm{~h}$, the strains were streaked onto tryptic soy agar (TSA) plates and continued to be incubated at $37^{\circ} \mathrm{C}$ for $24 \mathrm{~h}$. A typical colony was selected and inoculated into
$\mathrm{LB}$ broth at $37^{\circ} \mathrm{C}$ for $24 \mathrm{~h}$ to obtain the pure cultures of L. monocytogenes (Dias et al., 2018).

\section{Determination of Minimum Inhibitory Concentrations}

The MICs of OOPE against eight L. monocytogenes were determined using the agar dilution method according to previous report (Fei et al., 2018). L. monocytogenes cells were treated by different concentrations of OOPE $(10,5,2.5,1.25,0.625$, $0.3125,0.156$, and $0.078 \mathrm{mg} / \mathrm{ml}$ ), respectively, and $0.1 \mathrm{mg} / \mathrm{ml}$ ampicillin was used as the positive control. Two microliters of tested bacteria cultures was dripped onto the TSA plate, dried, and incubated at $37^{\circ} \mathrm{C}$ for $24 \mathrm{~h}$. The MIC was considered as the lowest concentration of OOPE, at which the visible growth of L. monocytogenes was inhibited completely.

\section{Reduction of $L$. monocytogenes CMCC 54004 by Olive Oil Polyphenol Extract in Normal Saline and Luria-Bertani}

L. monocytogenes CMCC 54004 was cultured in LB broth at $37^{\circ} \mathrm{C}$ for $24 \mathrm{~h}$, and then the density of strains was adjusted to about $10^{8} \mathrm{CFU} / \mathrm{ml}$ with sterile normal saline (NS) and diluted to about $10^{6} \mathrm{CFU} / \mathrm{ml}$ in $\mathrm{LB}$ as working cultures, respectively, according to the method reported by Bharitkar et al. (2014) with minor modifications. OOPE was dissolved in the working cultures (NS and LB) to obtain final concentrations of $0 \mathrm{MIC}, 1 \mathrm{MIC}$, and $2 \mathrm{MIC}$. Bacteria were further cultured, and bacterial suspensions were collected from NS and LB after $0.5,1,3,5$, and $7 \mathrm{~h}$, respectively. The diluted mixtures $(0.1 \mathrm{ml})$ were incubated on TSA at $37^{\circ} \mathrm{C}$ for $24 \mathrm{~h}$, and the survival population of L. monocytogenes CMCC 54004 was calculated.

\section{Measurement of Intracellular Adenosine 5'-Triphosphate Concentrations}

Based on the method described by Chen et al. (2017), the changes in intracellular ATP concentrations of L. monocytogenes CMCC 54004 after treatments with OOPE was measured. The final L. monocytogenes CMCC 54004 cell concentration was diluted to be $10^{8} \mathrm{CFU} / \mathrm{ml}$ with NS. The ATP assay kit (Beyotime Bioengineering Institute, Shanghai, China) was used to determine intracellular ATP concentration, and all processes were operated on an ice box. Two milliliters of cell suspensions containing different concentrations of OOPE (0 MIC, 1/4 MIC, 1/2 MIC, $1 \mathrm{MIC}$, and $2 \mathrm{MIC}$ ) was incubated at $37^{\circ} \mathrm{C}$ for $30 \mathrm{~min}$ and then mixed with lysis solution. The supernatant was obtained after centrifugation at $11,269 \times g$ for $5 \mathrm{~min}$ and stored in an ice box to prevent the loss of ATP. Both ATP test solution and supernatant were added to a colorless transparent 96-well plate (Corning Institute, USA) to determine intracellular ATP concentration with an Infinite 200 PRO multifunctional microplate reader (Tecan, Grodlg, Austria).

\section{Measurement of Membrane Potential}

The measurement of membrane potential was performed as previously described by Bharitkar et al. (2014). 
Bis-(1,3-dibutylbarbituric acid) trimethine oxonol $\left[\mathrm{DiBAC}_{4}(3)\right.$; Beijing Solarbio Science and Technology Co. Ltd., Beijing, China] was used as a membrane potential-sensitive fluorescent probe. Bacterial suspension and $\mathrm{DiBAC}_{4}(3)$ fluorescent probe were added in a black and opaque 96-well plate (Corning Institute, USA) to balance at $37^{\circ} \mathrm{C}$ for $30 \mathrm{~min}$. OOPE was then added in the 96-well plate to adjust the concentration to $0 \mathrm{MIC}$, 1 MIC, and 2 MIC, respectively. The fluorescence intensity of each well was recorded with a multifunctional microplate reader (Infinite 200 PRO, Tecan, Grodlg, Austria) under the condition of the excitation wavelength of $492 \mathrm{~nm}$ and emission wavelength of $515 \mathrm{~nm}$ at $37^{\circ} \mathrm{C}$. The value of relative fluorescence units (RFUs) was recorded as the result of membrane potential.

\section{Sodium Dodecyl Sulfate-Polyacrylamide Gel Electrophoresis}

The effect of OOPE on the bacterial protein was analyzed using the sodium dodecyl sulfate-polyacrylamide gel electrophoresis (SDS-PAGE) method as described by Chen et al. (2017). Approximately $10^{7} \mathrm{CFU} / \mathrm{ml}$ of L. monocytogenes CMCC 54004 cells was treated with OOPE at 0 MIC and $1 \mathrm{MIC}$ in NS at $37^{\circ} \mathrm{C}$. The bacterial suspensions were withdrawn every $3 \mathrm{~h}(3,6,9$, and $12 \mathrm{~h})$, washed three times using NS, and mixed with SDS-PAGE loading buffer $(\mathrm{pH} 6.8 ; 1.0 \mathrm{M}$ tris- $\mathrm{HCl}, 10 \%$ glycerol, $2 \%$ SDS, $10 \% \beta$-mercaptoethanol, and $0.1 \%$ bromophenol blue). After heating in boiling water bath for $10 \mathrm{~min}$, proteins were separated by SDS-PAGE using a concentrated gel (5\%) and a separated gel (15\%). Finally, gels were stained with Coomassie Brilliant Blue R250 (Sigma, USA). The image was taken with the HP scanner (HP 1000, USA).

\section{Transmission Electron Microscopy}

The cellular morphology of L. monocytogenes CMCC 54004 cells after treatments with 0 MIC, 1 MIC, and 2 MIC of OOPE was observed using the $\mathrm{H}-7650$ transmission electron microscope (TEM) (Hitachi, Tokyo, Japan) as described by Li et al. (2016). After treatments with different MICs of OOPE for $4 \mathrm{~h}$, L. monocytogenes CMCC 54004 cells were centrifuged at $5,008 \times g$ for $5 \mathrm{~min}$ and prefixed with $2.5 \%$ glutaraldehyde at $4^{\circ} \mathrm{C}$ for $2 \mathrm{~h}$. The pellets were rinsed with $0.1 \mathrm{M}$ sodium phosphate buffer ( $\mathrm{pH}$ 7.2) three times and postfixed with $1 \%$ osmium tetraoxide for $120 \mathrm{~min}$ and then rinsed three times again. The samples were dehydrated with different concentrations of ethanol $(50,70,90$, and $100 \%)$ for $10 \mathrm{~min}$ and infiltrated with the mixture of $100 \%$ acetone and Epon resin overnight at room temperature. The infiltrated samples were embedded in Epon Lx-112 (Ladd Research, Williston, VT) and polymerized at $70^{\circ} \mathrm{C}$ for $12 \mathrm{~h}$. Next, the samples were cut into sections of 50-60 nm, stained with uranyl acetate and lead citrate, and then observed under TEM.

\section{Agarose Gel Electrophoresis for DNA Fragmentation}

The effect of OOPE on the L. monocytogenes CMCC 54004 DNA was measured using agarose gel electrophoresis (AGE) according to previous report (Liu et al., 2011).
Approximately $10^{8} \mathrm{CFU} / \mathrm{ml}$ of L. monocytogenes cells were treated by $0 \mathrm{MIC}, 1 \mathrm{MIC}$, and $2 \mathrm{MIC}$ of OOPE in NS at $37^{\circ} \mathrm{C}$. The bacterial suspensions were treated for 2,4 , and $10 \mathrm{~h}$, respectively. The genomic DNA was extracted using a bacterial genomic DNA extraction kit (Tiangen Biotech Co., Ltd., Beijing, China). The DNA samples were electrophoresed using $1.5 \%$ agarose gel at $100 \mathrm{~V}$ for $30 \mathrm{~min}$. Finally, the gels were stained with $10 \mathrm{mg} / \mathrm{ml}$ of ethidium bromide for $15 \mathrm{~min}$ and visualized using a gel imaging system (Bio-Rad, USA).

\section{Statistical Analysis}

Experiments were repeated in triplicate, and data were analyzed using the SPSS 19.0 software (SPSS, Chicago, IL). All data are expressed as the mean values \pm standard deviation (SD). The statistical differences at 5\% significance level among means were determined by one-way analysis of variance (ANOVA).

\section{RESULTS}

\section{Minimum Inhibitory Concentrations of Olive Oil Polyphenol Extract Against L. monocytogenes Strains}

The results showed that OOPE had inhibitory ability against the growth of eight L. monocytogenes. Bacterial colony did not grow when the concentrations of OOPE were higher than or equal to $1.25 \mathrm{mg} / \mathrm{ml}$; therefore, the MIC of OOPE against eight L. monocytogenes was $1.25 \mathrm{mg} / \mathrm{ml}$.

\section{Reduction of L. monocytogenes CMCC 54004 by Olive Oil Polyphenol Extract in Normal Saline and Luria-Bertani}

The survival counts of $L$. monocytogenes CMCC 54004 in NS and LB after treatments with 1 MIC and 2 MIC of OOPE are shown in Figure 1. The results showed that the growth of L. monocytogenes treated by 1 MIC of OOPE were completely inhibited in NS after $7 \mathrm{~h}$ (Figure 1A). Meanwhile, L. monocytogenes could be completely inhibited after a treatment with 2 MIC of OOPE in LB after $7 \mathrm{~h}$ (Figure 1B).

\section{Determination of Intracellular Adenosine 5'-Triphosphate Concentrations}

As shown in Figure 2, the intracellular ATP concentration of L. monocytogenes CMCC 54004 was significantly reduced after treatments with different concentrations of OOPE for $30 \mathrm{~min}$ $(p<0.05)$, compared to the control group. Leakage of ATP in the cells of L. monocytogenes with the treatment of 2 MIC OOPE was detected to have lower ATP concentration than those of the control and 1 MIC OOPE. In addition, as the concentration of OOPE treatment increases, the intracellular ATP concentration in L. monocytogenes cell decreases.

\section{Changes in Membrane Potential}

As shown in Figure 3, compared with the control group, the fluorescence intensities of L. monocytogenes CMCC 54004 cells 


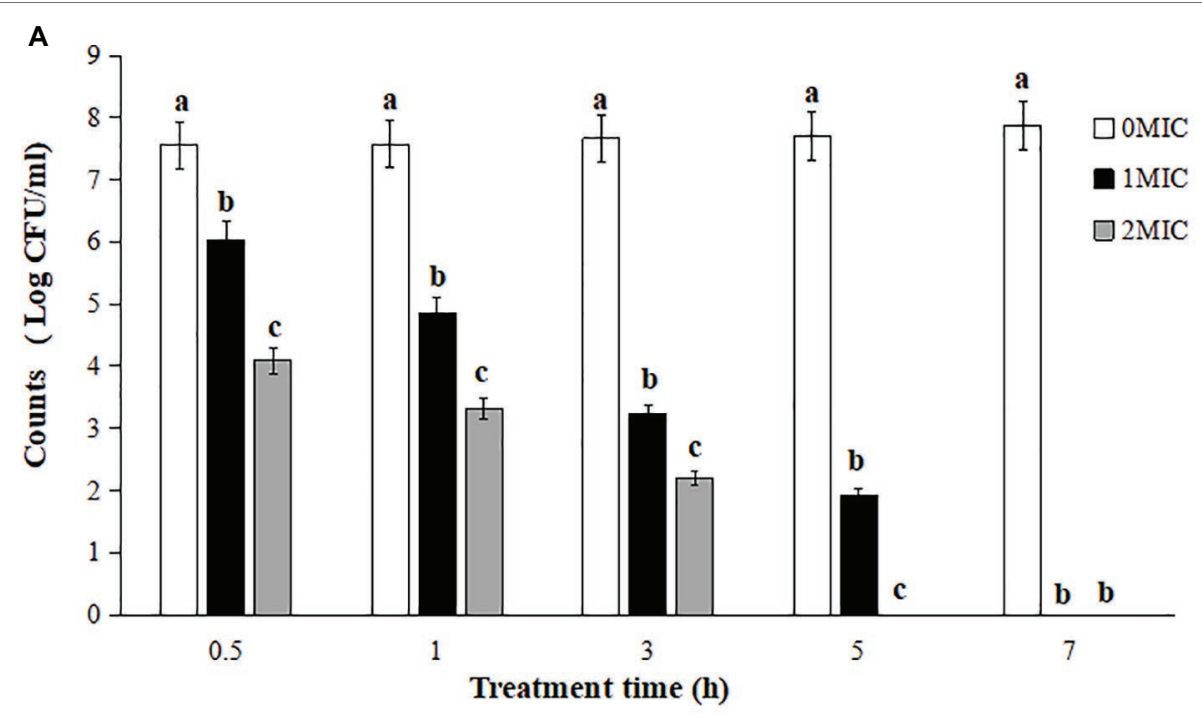

B

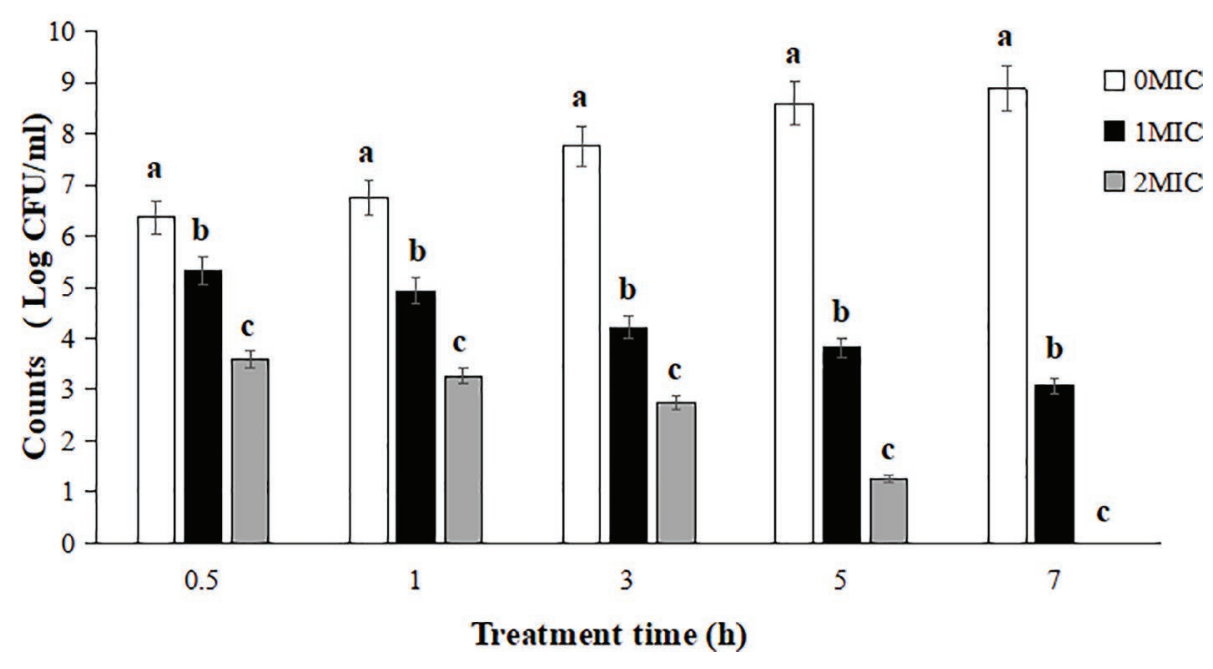

FIGURE 1 | Reduction of L. monocytogenes CMCC 54004 with treatments with different concentrations OOPE in NS (A) and LB (B). Error bars denote SD. Different letters denote significant differences between treatments within the same incubation time points $(p<0.05)$.

treated by 1 MIC and 2 MIC of OOPE were significantly increased $(p<0.05)$. It indicated that OOPE can cause the depolarization of L. monocytogenes cells. In addition, there is no difference in fluorescence intensity between the cell treatments with 1 MIC and 2 MIC of OOPE $(p>0.05)$.

\section{Sodium Dodecyl Sulfate-Polyacrylamide Gel Electrophoresis Analysis of} Bacterial Proteins

The SDS-PAGE image illustrated the effect of OOPE treatment on bacterial proteins of L. monocytogenes CMCC 54004 (Figure 4). The result showed that compared with the control group, the bacterial protein bands of L. monocytogenes CMCC 54004 treated by 1 MIC of OOPE begin to weaken after $3 \mathrm{~h}$. As OOPE treatment time increases, the bacterial protein bands become weaker. In addition, most of the bacterial protein bands of L. monocytogenes disappeared after treatment with OOPE for $6 \mathrm{~h}$.

\section{Transmission Electron Microscope Observation of Cell Morphology}

The cell morphology of L. monocytogenes CMCC 54004 cells treated by different levels of OOPE (0 MIC, $1 \mathrm{MIC}$, and $2 \mathrm{MIC}$ ) was observed (shown in Figure 5). The untreated strains showed regular cell morphology, with a normal short rod shape, intact cell structure, and a smooth and compact surface (Figure 5A). After treatment with $1 \mathrm{MIC}$ of OOPE for $4 \mathrm{~h}$, the cells showed morphological damage such as detachment of the cytoplasmic membrane from the cell wall, leakage of intracellular components, and deformation of cell (Figure 5B). Meanwhile, the cells treated by $2 \mathrm{MIC}$ of OOPE displayed more severe cell collapse and leakage (Figure 5C). 


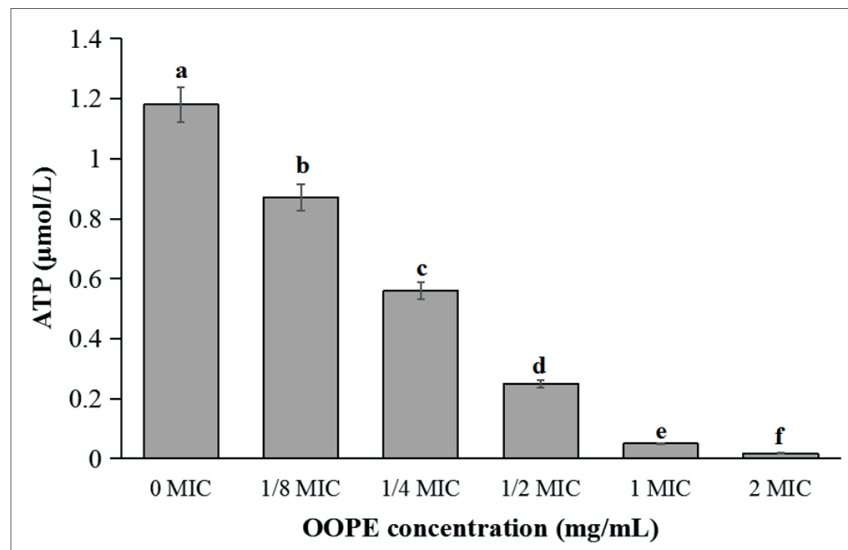

FIGURE 2 | Differences in intracellular ATP concentrations of L. monocytogenes CMCC 54004 following treatments with OOPE at O MIC, 1/8 MIC, 1/4 MIC, 1/2 $\mathrm{MIC}, 1 \mathrm{MIC}$, and $2 \mathrm{MIC}$. Values represent the means of independent triplicate measurements. Error bars denote SD. Different letters denote significant differences between treatments within the same incubation time points $(p<0.05)$.

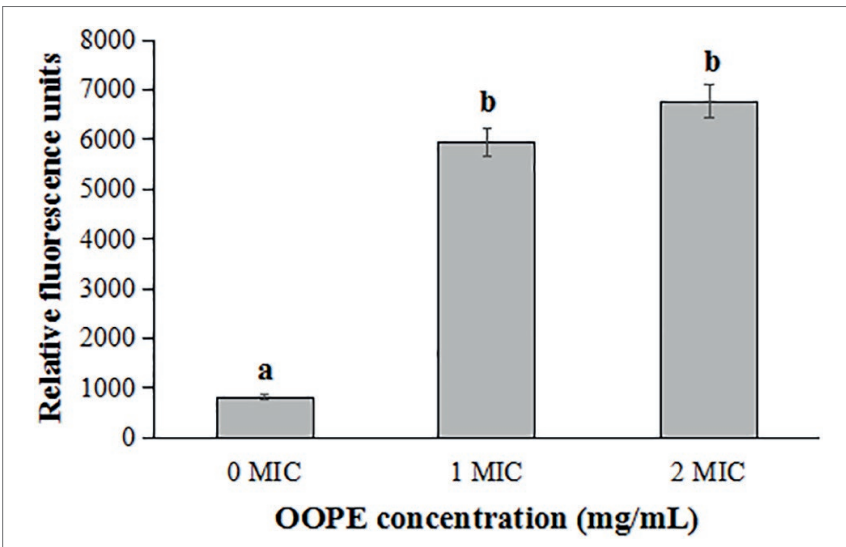

FIGURE 3 | Differences in membrane potentials of $L$. monocytogenes CMCC 54004 following treatments with OOPE at O MIC, $1 \mathrm{MIC}$, and $2 \mathrm{MIC}$. Values represent the means of independent triplicate measurements. Error bars denote SD. Different letters denote significant differences between treatments within the same incubation time points $(p<0.05)$.

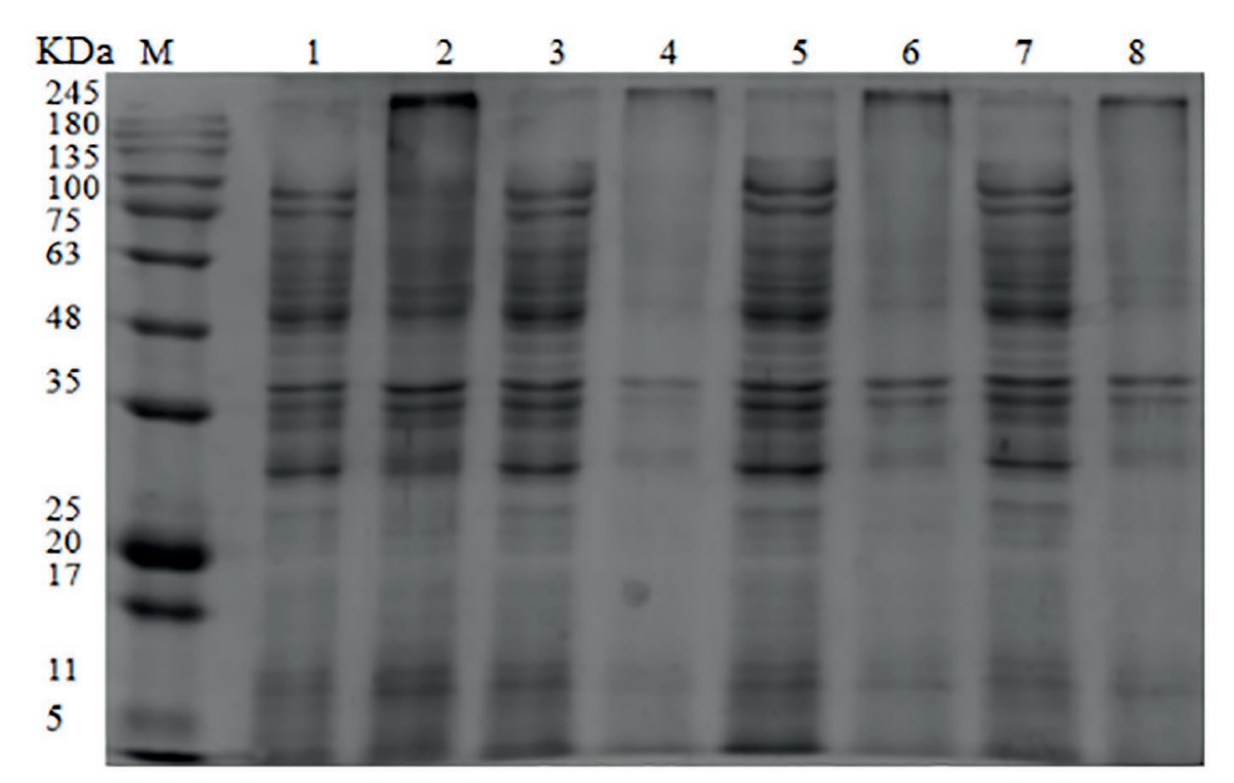

FIGURE 4 | SDS-PAGE analysis of L. monocytogenes CMCC 54004 proteins treated with OOPE at 0 MIC and 1 MIC. Lane M: marker. Lanes 1, 3, 5, and 7: treated with $0 \mathrm{MIC}$ of OOPE for 3, 6, 9, and 12 h, respectively. Lanes 2, 4, 6, and 8: treated with $1 \mathrm{MIC}$ of OOPE for 3, 6, 9, and 12 h, respectively.

\section{DNA Cleavage Analysis}

As shown in Figure 6, compared with the control group, the DNA bands of L. monocytogenes CMCC 54004 after exposure to OOPE were faint and became much fainter as the concentration of OOPE increased. Furthermore, after treatment with 2 MIC of OOPE for $4 \mathrm{~h}$, the DNA bands of L. monocytogenes disappeared.

\section{DISCUSSION}

Phenolic products consisting of polyphenol, flavonoids, and tannic acid have been reported to have satisfactory antibacterial activity against food-borne pathogens (Borges et al., 2013). Some studies have evaluated the antibacterial effects of ferulic acids, phenyllactic acid, and sugarcane bagasse extract (mainly containing phenolic substances) against $L$. monocytogenes strains, with MIC of $1.25 \mathrm{mg} / \mathrm{ml}$ (Zhao et al., 2015; Ning et al., 2017). In addition, the MICs of gallic acid, sugar beet molasses polyphenols, and cardoon polyphenols against $L$. monocytogenes strains were reported to be $1.60,5$, and $2.5-10 \mathrm{mg} / \mathrm{ml}$, respectively (Borges et al., 2013; Chen et al., 2017; Dias et al., 2018). In this study, the MIC of OOPE against eight $L$. monocytogenes strains was $1.25 \mathrm{mg} / \mathrm{ml}$, which suggested that the bacteriostatic activity of OOPE was worth affirming compared to the above natural extracts. 

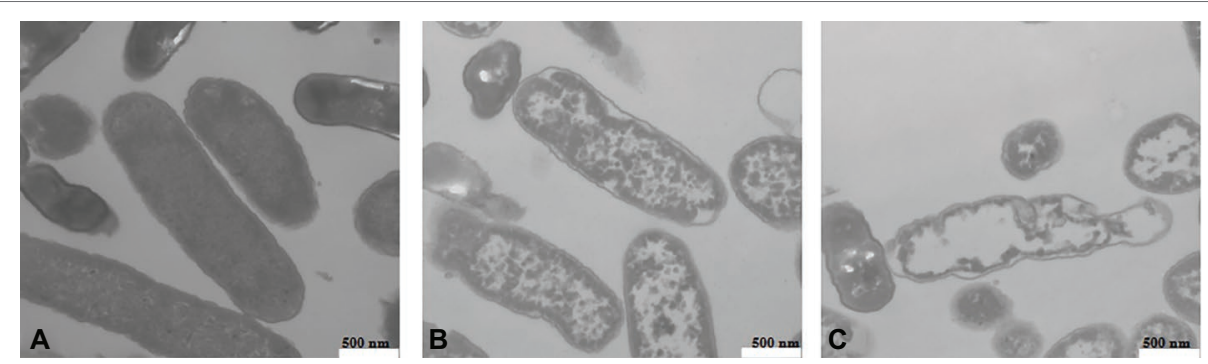

FIGURE 5 | TEM images of L. monocytogenes CMCC 54004 cells $(40,000 \times)$ (A) untreated for 4 h, (B) treated with 1 MIC of OOPE for 4 h, and (C) treated with 2 MIC of OOPE for $4 \mathrm{~h}$.

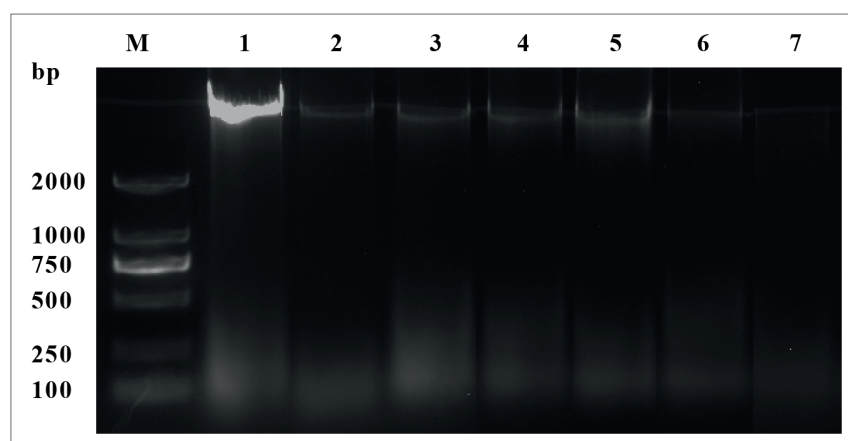

FIGURE 6 | DNA cleavage activity of L. monocytogenes CMCC 54004 strains treated with OOPE at O MIC, $1 \mathrm{MIC}$, and $2 \mathrm{MIC}$. Lane M: marker. Lane 1: control group. Lanes 2-4: treated with $1 \mathrm{MIC}$ of OOPE for 2, 4, and $10 \mathrm{~h}$, respectively. Lanes 5-7: treated with $2 \mathrm{MIC}$ of OOPE for 2, 4, and $10 \mathrm{~h}$, respectively.

In this study, the intracellular ATP concentration was significantly reduced after treatments with OOPE, which was consistent with the antibacterial action of OOPE against C. sakazakii and B. cereus (Fei et al., 2018, 2019). Similarly, Bendali et al. (2008) found that the antibacterial effect of the phenolic compounds of mangosteen against L. monocytogenes is related to the decrease in intracellular ATP level and suggested that the loss of ATP was allowed to be released during formation of pore complexes in the cells. In addition, Khan et al. (2017) reported that the loss of inorganic phosphate and $\mathrm{K}^{+}$in cells caused the reduction of intracellular ATP because the cells will consume available ATP in order to reaccumulate these ions. Shi et al. (2016) considered that the increased cell membrane permeability after treatments with natural product resulted in the release of ATP.

Resting membrane potential, as an important predictor of cell survival, was associated with cell antibiotic uptake and bactericidal action (Bot and Prodan, 2009). Our results showed that OOPE caused the immediate depolarization of L. monocytogenes cell membranes, which was considered as one of the important bacteriostatic pathways. Similarly, cell membrane depolarization was found in C. sakazakii and Escherichia coli cells after exposure to lipoic acid and carvacrol and was considered to be associated with less negative charges inside the cells (Silverman et al., 2003; Shi et al., 2016; Khan et al., 2017).

Differences in bacterial protein contents between untreated cells and ones treated with natural-occurring substance can be used to reveal the possible antibacterial action (Wang et al., 2015). Current studies suggested that after treatments with OOPE, the protein levels of L. monocytogenes cell were significantly reduced or almost disappeared. A similar action approach has been found by Chen et al. (2017), who illuminated that the bacterial protein bands of food-borne pathogens, including Staphylococcus aureus, L. monocytogenes, E. coli, and Salmonella typhimurium, became slighter and even disappeared after treatments with beet molasses polyphenols. Furthermore, the decrease in bacterial protein was considered to be related to reduction in protein synthesis and protein loss due to the increase in membrane permeability (Zeng et al., 2010; Fei et al., 2018).

TEM observation could help visually reveal the changes in cell morphology and cytoplasm of tested cells (Xing et al., 2009). After treatments with OOPE, the cell morphology of L. monocytogenes was severely destroyed and was accompanied by a large leakage of cell fluid, leading to cell death. Similar results have been reported by Barbosa et al. (2015), who found cell lysis, damage of cell wall, and leakage of cell contents occurred in L. monocytogenes treated by oregano essential oil containing thymol and carvacrol. In addition, the study of Borges et al. (2013) indicated one of the important reasons why ferulic and gallic acids can inhibit the growth of food-borne pathogenic bacteria was the irreversible changes in membrane change and leakage of intracellular components.

DNA, as the main genetic material, is considered the cornerstone of life's activities and is closely related to the bacterial growth, development, and inheritance (Cui et al., 2018). Combining the results of DNA fragmentation in this study, it can be supposed that OOPE may inhibit DNA synthesis or promote the cleavage of DNA of L. monocytogenes. Similarly, clove oil-containing phenols can inhibit the growth of L. monocytogenes, and DNA fragmentation appeared in treated cells (Cui et al., 2018). Besides, Wang et al. (2017) suggested that the phenolic components 
not only reduced the amount of DNA in cells by increasing cell membrane permeability and destroying the cell morphology but also bound to the minor groove of genomic DNA, resulting in changes in the secondary structure and morphology of DNA.

In conclusion, the present study indicated that OOPE has significant antibacterial activity against L. monocytogenes, and its antibacterial action was related to lower intracellular ATP, cell depolarization, decrease in bacterial protein and DNA, and cell fluid leakage due to destruction of cell morphology. These findings demonstrated that OOPE has potential as a food preservative to reduce the risk of contamination of L. monocytogenes. However, OOPE safety and specific application in food preservation need to be researched in the future.

\section{DATA AVAILABILITY}

All datasets generated for this study are included in the manuscript.

\section{REFERENCES}

Allen, K. J., Walecka-Zacharska, E., Chen, J. C., Katarzyna, K.-P., Devlieghere, F., Van Meervenne, E., et al. (2016). Listeria monocytogenes-an examination of food chain factors potentially contributing to antimicrobial resistance. Food Microbiol. 54, 178-189. doi: 10.1016/j.fm.2014.08.006

Araya-Cloutier, C., Vincken, J.-P., van Ederen, R., den Besten, H. M. W., and Gruppen, H. (2018). Rapid membrane permeabilization of Listeria monocytogenes and Escherichia coli induced by antibacterial prenylated phenolic compounds from legumes. Food Chem. 240, 147-155. doi: 10.1016/j. foodchem.2017.07.074

Aureli, P., Costantini, A., and Zolea, S. (1992). Antimicrobial activity of some plant essential oils against Listeria monocytogenes. J. Food Prot. 55, 344-348. doi: 10.4315/0362-028X-55.5.344

Barbosa, L. N., Probst, I. S., Murbach Teles Andrade, B. F., Bergamo Alves, F. C., Albano, M., Mores Rall, V. L., et al. (2015). Essential oils from herbs against food-borne pathogens in chicken sausage. J. Oleo Sci. 64, 117-124. doi: 10.5650/jos.ess 14163

Bendali, F., Gaillard-Martinie, B., Hebraud, M., and Sadoun, D. (2008). Kinetic of production and mode of action of the Lactobacillus paracasei subsp. paracasei anti-listerial bacteriocin, an Algerian isolate. LWT-Food Sci. Technol. 41, 1784-1792. doi: 10.1016/j.lwt.2008.02.010

Bharitkar, Y. P., Bathini, S., Ojha, D., Ghosh, S., Mukherjee, H., Kuotsu, K., et al. (2014). Antibacterial and antiviral evaluation of sulfonoquinovosyldiacylglyceride: a glycolipid isolated from Azadirachta indica leaves. Lett. Appl. Microbiol. 58, 184-189. doi: 10.1111/lam.12174

Borges, A., Ferreira, C., Saavedra, M. J., and Simoes, M. (2013). Antibacterial activity and mode of action of ferulic and gallic acids against pathogenic bacteria. Microb. Drug Resist. 19, 256-265. doi: 10.1089/mdr. 2012.0244

Bot, C., and Prodan, C. (2009). Probing the membrane potential of living cells by dielectric spectroscopy. Eur. Biophys. J. 38, 1049-1059. doi: 10.1007/ s00249-009-0507-0

Bubonja-Sonje, M., Giacometti, J., and Abram, M. (2011). Antioxidant and antilisterial activity of olive oil, cocoa and rosemary extract polyphenols. Food Chem. 127, 1821-1827. doi: 10.1016/j.foodchem.2011.02.071

Chen, M., Zhao, Z., Meng, H., and Yu, S. (2017). Antibiotic activity and mechanisms of sugar beet (Beta vulgaris) molasses polyphenols against selected food-borne pathogens. LWT-Food Sci. Technol. 82, 354-360. doi: 10.1016/j.lwt.2017.04.063

\section{AUTHOR CONTRIBUTIONS}

PF, SG, LG, WJ, and WX conceived and designed the experiments. QS, SG, and XB performed the experiments. LG, PF, SG, and QS generated and analyzed the data. LG, PF, and QS wrote the paper.

\section{FUNDING}

This research was supported by the open fund of the Key Laboratory of Dairy Science of the Ministry of Education at Northeast Agricultural University (2017KLDS06) and the Doctor Scientific Research Start-up Fund of Henan University of Science and Technology (13480066).

\section{ACKNOWLEDGMENTS}

The authors thank the anonymous referees and editors for their valuable advice.

Cui, H. Y., Zhang, C. H., Li, C. Z., and Lin, L. (2018). Antimicrobial mechanism of clove oil on Listeria monocytogenes. Food Control 94, 140-146. doi: 10.1016/j.foodcont.2018.07.007

Daglia, M. (2012). Polyphenols as antimicrobial agents. Curr. Opin. Biotechnol. 23, 174-181. doi: 10.1016/j.copbio.2011.08.007

Dias, M. I., Barros, L., Barreira, J. C. M., Alves, M. J., Barracosa, P., and Ferreira, I. C. F. R. (2018). Phenolic profile and bioactivity of cardoon (Cynara cardunculus L.) inflorescence parts: selecting the best genotype for food applications. Food Chem. 268, 196-202. doi: 10.1016/j.foodchem. 2018.06.081

Fei, P., Ali, M. A., Gong, S., Sun, Q., Bi, X., Liu, S., et al. (2018). Antimicrobial activity and mechanism of action of olive oil polyphenols extract against Cronobacter sakazakii. Food Control 94, 289-294. doi: 10.1016/j.foodcont. 2018.07.022

Fei, P., Xu, Y. F., Zhao, S. J., Gong, S. Y., and Guo, L. (2019). Olive oil polyphenols extract inhibits vegetative cells of Bacillus cereus isolated from raw milk. J. Dairy Sci. 102, 3894-3902. doi: 10.3168/jds.2018-15184

Hamidi-Oskouei, A. M., James, C., and James, S. (2015). The efficiency of UVC radiation in the inactivation of Listeria monocytogenes on beef-agar food models. Food Technol. Biotechnol. 53, 231-236. doi: 10.17113/ $\mathrm{ftb} .53 .02 .15 .3966$

Khan, I., Bahuguna, A., Kumar, P., Bajpai, V. K., and Kang, S. C. (2017). Antimicrobial potential of carvacrol against uropathogenic Escherichia coli via membrane disruption, depolarization, and reactive oxygen species generation. Front. Microbiol. 8:2421. doi: 10.3389/fmicb.2017.02421

Li, R., Fei, P., Man, C. X., Lou, B. B., Niu, J. T., Feng, J., et al. (2016). Tea polyphenols inactivate Cronobacter sakazakii isolated from powdered infant formula. J. Dairy Sci. 99, 1019-1028. doi: 10.3168/jds.2015-10039

Liu, X. L., Zhang, X. J., Fu, Y. J., Zu, Y. G., Wu, N., Liang, L., et al. (2011). Cajanol inhibits the growth of Escherichia coli and Staphylococcus aureus by acting on membrane and DNA damage. Planta Med. 77, 158-163. doi: $10.1055 / \mathrm{s}-0030-1250146$

Long, Y., Zhou, X., and Xing, D. (2011). Sensitive and isothermal electrochemiluminescence gene-sensing of Listeria monocytogenes with hyperbranching rolling circle amplification technology. Biosens. Bioelectron. 26, 2897-2904. doi: 10.1016/j.bios.2010.11.034

Ning, Y. W., Yan, A. H., Yang, K., Wang, Z. X., Li, X. F., and Jia, Y. M. (2017). Antibacterial activity of phenyllactic acid against Listeria monocytogenes and Escherichia coli by dual mechanisms. Food Chem. 228, 533-540. doi: 10.1016/j. foodchem.2017.01.112 
Odedina, G. F., Vongkamjan, K., and Voravuthikunchai, S. P. (2015). Potential bio-control agent from Rhodomyrtus tomentosa against Listeria monocytogenes. Nutrients 7, 7451-7468. doi: 10.3390/nu7095346

Rendueles, E., Omer, M. K., Alvseike, O., Alonso-Calleja, C., Capita, R., and Prieto, M. (2011). Microbiological food safety assessment of high hydrostatic pressure processing: a review. LWT-Food Sci. Technol. 44, 1251-1260. doi: 10.1016/j.lwt.2010.11.001

Shi, C., Sun, Y., Zheng, Z. W., Zhang, X. R., Song, K. K., Jia, Z. Y., et al. (2016). Antimicrobial activity of syringic acid against Cronobacter sakazakii and its effect on cell membrane. Food Chem. 197, 100-106. doi: 10.1016/j. foodchem.2015.10.100

Silverman, J. A., Perlmutter, N. G., and Shapiro, H. M. (2003). Correlation of daptomycin bactericidal activity and membrane depolarization in Staphylococcus aureus. Antimicrob. Agents Chemother. 47, 2538-2544. doi: 10.1128/ AAC.47.8.2538-2544.2003

Tafesh, A., Najami, N., Jadoun, J., Halahlih, F., Riepl, H., and Azaizeh, H. (2011). Synergistic antibacterial effects of polyphenolic compounds from olive mill wastewater. Evid. Based Complement. Alternat. Med. 2011, 1-9. doi: $10.1155 / 2011 / 431021$

Thielmann, J., Kohnen, S., and Hauser, C. (2017). Antimicrobial activity of Olea europaea Linne extracts and their applicability as natural food preservative agents. Int. J. Food Microbiol. 251, 48-66. doi: 10.1016/j. ijfoodmicro.2017.03.019

Wang, C. J., Chang, T., Yang, H., and Cui, M. (2015). Antibacterial mechanism of lactic acid on physiological and morphological properties of Salmonella Enteritidis, Escherichia coli and Listeria monocytogenes. Food Control 47, 231-236. doi: 10.1016/j.foodcont.2014.06.034

Wang, L. H., Zhang, Z. H., Zeng, X. A., Gong, D. M., and Wang, M. S. (2017). Combination of microbiological, spectroscopic and molecular docking techniques to study the antibacterial mechanism of thymol against
Staphylococcus aureus: membrane damage and genomic DNA binding. Anal. Bioanal. Chem. 409, 3055-3055. doi: 10.1007/s00216-017-0264-3

Xing, K., Chen, X. G., Kong, M., Liu, C. S., Cha, D. S., and Park, H. J. (2009). Effect of oleoyl-chitosan nanoparticles as a novel antibacterial dispersion system on viability, membrane permeability and cell morphology of Escherichia coli and Staphylococcus aureus. Carbohydr. Polym. 76, 17-22. doi: 10.1016/j. carbpol.2008.09.016

Xylia, P., Chrysargyris, A., Botsaris, G., and Tzortzakis, N. (2018). Mint and pomegranate extracts/oils as antibacterial agents against Escherichia coli O157:H7 and Listeria monocytogenes on shredded carrots. J. Food Saf. 38:e12423. doi: $10.1111 /$ jfs. 12423

Zeng, X. P., Tang, W. W., Ye, G. Q., Ouyang, T., Tian, L., Ni, Y. M., et al. (2010). Studies on disinfection mechanism of electrolyzed oxidizing water on E. coli and Staphylococcus aureus. J. Food Sci. 75, M253-M260. doi: 10.1111/j.1750-3841.2010.01649.x

Zhao, Y., Chen, M. S., Zhao, Z. G., and Yu, S. J. (2015). The antibiotic activity and mechanisms of sugarcane (Saccharum officinarum L.) bagasse extract against food-borne pathogens. Food Chem. 185, 112-118. doi: 10.1016/j. foodchem.2015.03.120

Conflict of Interest Statement: The authors declare that the research was conducted in the absence of any commercial or financial relationships that could be construed as a potential conflict of interest.

Copyright (c) 2019 Guo, Sun, Gong, Bi, Jiang, Xue and Fei. This is an open-access article distributed under the terms of the Creative Commons Attribution License (CC BY). The use, distribution or reproduction in other forums is permitted, provided the original author(s) and the copyright owner(s) are credited and that the original publication in this journal is cited, in accordance with accepted academic practice. No use, distribution or reproduction is permitted which does not comply with these terms. 